\title{
The Treasure House of Nature
}

\section{By J. W. S. Pringle, F.R.S.}

In the conclusion of his presidential address to the Zoology Section of the British Association meetings in Nottingham last September, Professor Pringle, Linacre Professor of Zoology at Oxford, stressed the urgent need to conserve every kind of wildlife because of its importance for the advancement of knowledge.

$W^{E}$ zoologists, more than anyone else, ought to be conscious of the value of what the treasure-house of nature contains. It is a priceless reservoir of knowledge, left to us by millions of years of natural evolution and forming an irreplaceable mine of information about the machinery of life, including our own life. Are we doing enough to look after it and to protect it long enough for the message it can give us to become available for the benefit of mankind? This, surely, is an important duty.

Now I know that in recent years, there has been a gradual awakening in western countries to the need for conservation. More than any one event, it was the publication of Rachel Carson's book, Silent Spring, that stimulated this revival of interest. We now have our Nature Reserves, National Parks, the World Wildlife Fund and other important and laudable endeavours. I do not want to say much about these, because other people could do it better. But I want to suggest that among the objectives of conservation we have overlooked one very important one. Most people who are aware of the need for conservation would probably say that its objective is to preserve the general amenities of life, so that others may enjoy the beauties of nature. This is certainly important. If they were a little more far-sighted, they might say that a second objective is to preserve the animals and plants that are directly important for man's livelihood or that might become important in the future. I mean such measures as not killing off all the pollinating bees by spraying crops while they are in flower, as was recommended recently in a leaflet issued by the Royal Horticultural Society about the control of big-bud in black-currants. Or even by not destroying all the rough ground in which bumble bees breed, whatever the farmers may say about the spread of weeds.

These two objectives of conservation are becoming generally appreciated. The objective I am stressing is different. It is that we should not destroy the potential contained in the animal kingdom for the future advancement of knowledge. I believe that this is a real objective and an important one, not only to the research worker who may otherwise be deprived of the use of the animal or plant which has been 'created' for his purpose, but to mankind as a whole for the benefits which research brings. This is not an entirely new point of view, though it is infrequently expressed. For instance, Dr P. J. Newbould, 
writing on 'The material benefits of conservation' in the New Scientist for March 28, 1963, wrote of 'the necessity of conserving genetic variety, at least on a world basis'. He was thinking here of the potential value of new species to the animal or plant breeder trying to produce food more efficiently, but the need to conserve the variety of nature arises also for the reasons $I$ have given.

The difficulty arises from the unknown nature of the future need. We do not know where in biology any given line of enquiry is going to lead us or what hitherto unthought of problem may require a particular species of animal for its solution. But we cannot afford to destroy any opportunity for, once gone, it can never be restored. This is our problem. Elucidation of the mechanisms of life is difficult enough as it is, by the very nature of the problem. Must we, by neglect, or even by our own positive actions, make the task more difficult for ourselves and our successors? If we do allow a species to die out, the opportunity to learn from it has gone for ever and we shall never know what immense benefits might have been obtained. The ferret still survives. The susceptibility of the ferret to the virus of human influenza was, at one time, an important factor in progress towards the control of this disease. No one can say that there may not have been some peculiar feature of the great auk which would have enabled us by now to have found the answer to some other human medical problem. I know this will sound far-fetched, but it is a valid statement. The chance that the great auk could have helped may be very small; the point is that now we shall never know. If things go on as they are, there will soon be a large number of wasted opportunities of this sort and the chances that essential material will be lost will be very great.

What can we zoologists do about this? It is a very much more difficult aspect of conservation than those usually mentioned, for we have to try to conserve not only the large and obviously attractive speoies, like the mammals, but everything that the process of natural evolution has given us for our future enlightenment, the insects and other small invertebrates as well as the larger species. If the march of material progress makes it inevitable that whole environments will be destroyed and all the animals and plants that live in them, one thing we can do is to urge the necessity for living museums, for artificially maintained nucleus stocks of the material which would otherwise be lost. This means a new and expanded rôle for zoological gardens. I suggest that the benefit and value to mankind in the future would be as great as that conferred by all the art museums of the world put together. This should be a real claimant for public support.

Then we should urge the importance of more study of natural environments, so that we can know what is the minimum that must be retained if species are not to die out. This will very often be more economical than the maintenance of artificial cultures, which may well be impossible for a large number of species of animal. Having established this minimum, we should urge this interest over all others. And I mean all others. No amount of immediate need can possibly 
counterbalance the advantage to mankind over the whole of future time. This is where we have got to adopt a new tone of voice. As Elspeth Huxley said recently in an article in that fine magazine Animals, 'there will have to be more than uneasiness, there will have to be anger if the outlook is to be changed'. If the zoological community is convinced of the irreplaceable value of a stock of animals, any measure is justified to stop it being destroyed. If a burglar is breaking into your house, you are justified in stopping him 'by any reasonable means'. The community now may disapprove. Mankind in the future will be grateful.

We must also put our own house in order. Uncontrolled exploitation of a species of animal or plant for research and teaching purposes can easily remove it from the realm of usefulness. In our efforts to teach biology to our students in schools and universities, we have now almost eliminated the common frog from the fauna of the British Isles. We have depleted the fauna of the sea round marine biological stations to the point where irreversible changes may have been caused in the natural environments. Physiologists now compete with one another for the remaining specimens of the squid which can be obtained near the British Isles, and I believe it is even worse in North America. Of course, this sort of predation fortunately does not often wipe out a species; the natural equilibrium of animal populations is such that one does not usually eliminate a complete species by such a densitydependent factor as collecting for research and teaching. But we do cut our own throats if the discovery and use of a valuable species is not also accompanied by proper study of its natural habitat and way of life. There ought at this moment to be in progress a massive research programme on the ecology of the frog and the squid, if these two are indeed unique animals for teaching and research. The problem is going to get a lot worse when the new curricula of biology teaching in schools gets under way, with their demand for a much greater variety of animals. Who is going to supply these? And if someone does take on the job of providing them, what safeguards have we that they will not be content to rely on the so-called natural supply, that supposedly inexhaustible reservoir of life which is so rapidly being exhausted? Surely this is a proper subject for the British Association for the Advancement of Science.

As we enjoy the survey of the subject that our lecturers here give us, let us not forget that we and they are living on borrowed time. We have got by so far and we can no doubt continue to get by for a short while by acting as predators on a bounteous nature which provides us with the material which we study. But let us not forget our guardianship. Let it not be said by future generations that we ourselves have despoiled the treasure-house of nature and done nothing to prevent it falling into decay.

Reproduced by kind permission from "The Advancement of Science," Vol. 23, No. 112, Oct. 1966. 